\title{
LUSITÂNIA DE ALMEIDA FARIA: UM ROMANCE EPISTOLAR QUE CRUZA FICÇÃO HISTORIOGRÁFICA E TESTEMUNHO AUTOBIOGRÁFICO
}

\author{
LUSITANIA BY ALMEIDA FARIA: BETWEEN \\ HISTORIOGRAPHICAL FICTION AND \\ AUTOBIOGRAPHICAL TESTIMONY
}

Agnès Levécot ${ }^{1}$

\section{RESUMO}

Lusitânia de Almeida Faria é um romance epistolar em que se cruzam cartas de diversos membros de uma mesma família da burguesia latifundiária da região do Alentejo. Afastados por razões ligadas à evolução político-social de Portugal durante o ano de 1974, as personagens evocam o seu estado de espírito, os seus pensamentos mas sobretudo as suas dúvidas e angústias perante o transtorno político e as suas primeiras consequências. Mostramos neste artigo como a estrutura desta narrativa epistolar polifónica acentua o desconcerto pós-25 de Abril duma parte da população portuguesa, desconcerto relatado aliás em grande parte da produção romanesca do último quarto do século $\mathrm{XX}$, mas que revela paralelamente o ceticismo do próprio autor para com a evolução do seu país.

PALAVRAS-CHAVE: ficção historiográfica, identidade, epistolar.

\section{ABSTRACT}

Lusitania by Almeida Faria is an epistolary novel in which we witness the correspondence exhanged among several members descending from the same middle class family, bourgeois countrymen. Far apart, due to political and social evolution reasons, linked to the period, throughout the year of 1974, the characters tell each other their thoughts, their reactions (or 
lack of reaction), but, above all, their doubts regarding the political upheaval and its first consequences. We will show how the narrative's epistolary polyphonic structure underlines the post-April 25th distress felt by part of the Portuguese population and which is widely represented in the Portuguese novel from the end of the 20th century. However, this also reveals the author's scepticism concerning the evolution of his country.

KEYWORDS: historiographical fiction, autobiographical fiction, identity, epistolary, polyphony.

Lusitânia é o terceiro volume duma tetralogia que tem uma génese original: a partir de um primeiro romance publicado em 1965 que relata a vida de uma família latifundiária da região do Alentejo, Almeida Faria prolongou, após a Revolução dos Cravos, a história desta mesma família ao longo de três outros volumes, num efeito de construção retrospetiva. No conjunto desta obra, o autor faz pensar e evoluir as suas personagens paralelamente aos acontecimentos, numa narrativa articulada em função de ciclos simultaneamente cósmicos, históricos e litúrgicos, na base do calendário pascal. Veremos como, retomando as palavras de Luís de Sousa Rebelo na sua introdução à quinta edição do romance, "o tempo da Paixão constitui um rito prefigurador e perversamente cumprido na vida das personagens e no destino histórico, que é o da velha Lusitânia" (Rebelo, 1992, p. 12).

Para melhor compreender a originalidade da construção da tetralogia, convém apresentar sucintamente os romances anteriores. No primeiro romance, Paixão (1965), o relato corre durante um ciclo diário, sendo este dia uma Sexta-Feira Santa. Treze anos mais tarde, o autor retoma e prolonga a primeira narrativa relatando a vida da família num sábado santo: o segundo romance da tetralogia, Cortes (1978), anuncia a rutura que se efetivou com o golpe de estado de 25 de Abril de 1974, evento que, no romance seguinte, Lusitânia (1980) é simbolicamente evocado como possível ressurreição já que a primeira carta é assinada por João Carlos (aliás J. C.) no dia 14 de Abril de 1974, ou seja no domingo de Páscoa do mesmo ano. Este romance é dividido em três partes cujos títulos remetem para três grandes momentos do processo revolucionário: "Águas Mil” refere-se aos dias que precederam e sucederam imediatamente ao golpe militar (a expressão remete para o ditado português que afirma "Abril, águas mil"), "Setembro negro" diz respeito à tentativa de golpe contrarrevolucionário do General Spínola em 28 de Setembro de 1974, e "Idos de Março" evoca o período de afirmação dos partidos de ideologia marxista no processo revolucionário, com a tentativa de golpe de extrema esquerda no dia 11 de Março de 1975. Note-se que estes títulos constituem as referências mais explícitas aos momentos políticos, registos estes que obrigam o leitor a estabelecer um paralelo entre calendário litúrgico e calendário político, pois esses marcos do vaivém revolucionário são muito raramente mencionados 
como tais, ou, se comentados pelos epistolários, são-no apenas em correlação com a vida da família. "O ritmo da narrativa (escreve a este propósito L. S. Rebelo) não depende tanto do curso dos acontecimentos como da leitura que as personagens deles fazem, dos seus modos de sentir e das atitudes que elas são obrigadas a tomar perante eles" (Rebelo, 1992, p. 21). O quarto romance, o Cavaleiro Andante (1983) corre durante o período de rescaldo da revolução, de Junho a Novembro de 1975, cujo dia 25 marcou o fim do processo revolucionário.

Dum ponto de vista genérico, os últimos dois romances são relatos epistolares em que se cruzam as cartas dos diversos membros da família espalhados pelo mundo lusófono, por razões geralmente relacionadas com a situação política portuguesa. O objeto deste artigo será, restringindo o nosso corpus ao romance Lusitânia, analisar como o tratamento temático e narrativo da história desta família salienta a desilusão que marcou grande parte da população portuguesa, mas também o ceticismo do autor em relação à capacidade de evolução do seu país. Veremos como o processo epistolar polifónico permite dar conta dos acontecimentos e das tensões sociopolíticas da época assim como da desilusão pós-revolucionária e do questionamento identitário que a revolução política gerou, fazendo com que este romance possa ser lido como uma ficção historiográfica. Por outro lado, interrogar-nos-emos sobre o género desta narrativa e particularmente sobre o seu carácter testemunhal mostrando como as trocas epistolares fictícias permitem combinar historiografia, biografia e autobiografia.

A estrutura narrativa de Lusitânia apresenta-se complexa, sendo distribuída por várias vozes e vários tipos de discursos. Adoptando neste romance principalmente o género epistolar, o autor faz com que os membros duma mesma família se escrevam de três espaços diferentes - Veneza, Montemínimo (propriedade rural da família), Lisboa e Luanda. Completando esta troca epistolar, intervêm outros tipos de discursos, em forma de monólogos transmitidos por um narrador onisciente, daqueles que não estão em idade de escrever cartas por serem mais novos (os irmãos Jó e Tiago) ou por serem analfabetos (Moisés), completados por excertos de diários íntimos de duas mulheres, Marina, a mãe, e Estela, a criada.

Vejamos, num primeiro tempo, como a construção epistolar permite desenvolver uma dialéctica entre ficção e realidade, já que, imitando a carta real, a carta fictícia introduz no romanesco a ilusão do real. Esta dialéctica é reflexivamente evocada pela personagem principal na primeira carta enviada aos pais: "Estou mesmo a ver a vossa cara ao receberem esta, enviado do estrangeiro, contando factos em que eu mesmo custo a crer" $\left(L u s^{2}, 29\right)$. A leitura da carta escrita dá a sensação de ouvirmos uma pessoa verdadeira e não uma personagem de romance, impressão reforçada pela menção de datas precisas, de locais reais e de eventos reconhecidamente históricos, que, no entanto, não garantem a autenticidade e a objetividade do relato. Pois, nestas trocas epistolares, cada interveniente dá a sua própria versão da realidade daquilo que está vivendo, cada qual propondo uma 
evocação diferente da dita realidade. Entretanto, neste caso preciso, a interpretação do leitor é limitada por dois factores essenciais: todas as personagens se movem num ambiente extremamente disfórico e a construção polifónica, suscetível de apresentar uma visão múltipla do momento nacional, acaba ampliando o efeito de desilusão. A alegria e o entusiasmo da maior parte da população portuguesa, quando da queda do totalitarismo, não tem quase nenhuma representação textual, o autor deixando, assim, transparecer a sua própria visão pessimista quanto à evolução do processo político-social, o que nos autoriza a questionar a dimensão autobiográfica deste romance.

A vida de Almeida Faria apresenta efetivamente muitos pontos comuns com a história dos Cantares, entre outros as suas origens sociais e geográficas já que nasceu e cresceu numa família da burguesia alentejana (mais precisamente em Montemor-o-Novo). É, portanto, fácil imaginar que o autor se refere aqui a situações e acontecimentos que ele próprio viveu, e que ele relata através dum olhar fortemente impregnado de subjetividade. Assim sendo, este texto pode ser lido como um destes romances autobiográficos que Georges May classifica na categoria dos relatos que constituem uma "transposição mais ou menos transparente da vida do autor” (May, 1979, p. 188) ${ }^{3}$. Esta abordagem da dimensão autobiográfica da produção romanesca é partilhada por pensadores que se debruçaram sobre a interrelação entre memória individual e coletiva, como o sociólogo Maurice Halbwachs (1997) ou os filósofos Paul Ricœur (2000) e Georges Gusdorf (1991), este último afirmando que "A história das sociedades e dos indivíduos constitui uma das dimensões da nossa memória; o nosso passado pessoal comunica muito naturalmente com o passado familiar, provincial, nacional e universal" (Gusdorf, 1991, p. 325). No entanto, como observa Bruno Blanckeman, a autobiografia, "dependente do sujeito como instância movente, escreve-se no entre-deux das palavras, dos relatos e dos géneros" (Blankeman, 2002, p. 113). Com efeito, mesmo que reconheçamos aqui alguma matéria autobiográfica, a intenção do autor será, antes de mais, questionar o estado de uma nação através de uma microestrutura social, a célula familiar Cantares, que representa metonimicamente o país inteiro, a começar pela personagem do pai Francisco "que se mumificara, nada fazendo para entender os novos tempos" (Cortes $\left.{ }^{4}, 109\right)$, ponto de vista que traduz a aversão à autoridade dominadora: homem autoritário, tiránico, o patriarca está claramente aparentado à figura do chefe de estado António de Oliveira Salazar que governou até 1968 impondo um regime ditatorial ${ }^{5}$. Entretanto, o país está a viver grandes mutações que se espelham na errância geográfica e mental das personagens profundamente marcadas pelo peso de cinco décadas de poder totalitário de que dificilmente se libertam. Os indivíduos sentem-se perdidos perante uma situação complexa para a qual não estavam em nada preparados: Arminda procura "o ritmo certo desta festa ainda indecisa acerca de qual dos caminhos a seguir" (Lus, 122). As incertezas e as angústias que esta situação acarreta também fazem 
com que Marta se sinta destabilizada e indague a sua própria identidade interrogando as suas reminiscências camonianas: "dei por mim a recitar 'esta é a ditosa pátria minha amada' ${ }^{6}$ e semelhantes disparates, eu que dantes vomitava ao ouvir tais chavões nacionais" (Lus, 40). Por outro lado, o fato de o romance ser dedicado a Eduardo Lourenço, pensador maior da identidade portuguesa e que questiona largamente a realidade cultural, histórica e política da sua nação, é, neste sentido, muito significativo. Aliás, o próprio título do romance constitui em si o primeiro índice do diálogo que o autor pretende estabelecer com a história nacional. Além disso, cruzando as referências intertextuais camonianas com as indicações calendárias do período histórico evocado, o autor não deixa dúvida quanto à sua intenção: o conjunto das personagens desta ficção, que exprimem separadamente os seus pensamentos e sentimentos sobre os acontecimentos vividos por elas, representa conjunta e metonimicamente a matéria coletiva. Disto tem plena consciência João Carlos, que deseja "terminar depressa esta agonia, este estertor nacional de que o micro Montemínimo é apenas o cadinho" (Lus, 228). Para além disso, a escolha do género epistolar em que a instância narrativa se divide entre várias vozes permite ao autor ultrapassar o caráter artificial e unilateral do relato histórico convencional, expressando pela reformulação literária a consciência individual e coletiva ao mesmo tempo que a indagação identitária que lhe é subjacente. Assim, o desentendimento e o conflito latente que caraterizam as relações entre o pai Francisco e o filho J. C. que, no final do romance anterior, Cortes, levou a que este último abandonasse a propriedade familiar sem aviso prévio, representa metaforicamente o mal estar de uma geração que não se reconhece na sociedade em que cresceu e na noção de pátria imposta pelo antigo regime. Por isso, empreendem as personagens viagens erráticas que, segundo Salah Stétié, são derivadas de uma "falha identitária" (Stétié, 1994, p. 8), e que constituem, portanto, uma manifestação da deficiência identitária acarretada pelo caos político-social do momento.

Através da história da família Cantares, o autor interroga, portanto, a evolução dum país todo, evolução que, como já foi dito anteriormente, é vista como negativa. A sua evocação constrói-se na base de uma poética da ruína anunciada logo na epígrafe, citação de Eça de Queirós: "pátria para sempre passada, memória quase perdida”. A tonalidade pessimista é desde o início reforçada pela descrição que faz da cidade de Lisboa a personagem principal quando atravessa o rio Tejo. A bordo do cacilheiro, João Carlos descreve um rio e uma cidade em estado avançado de degradação, observação e sentimento reveladores do estado de espírito que o levou a abandonar família e pátria:

um daqueles cacilheiros iguais aos de quando éramos pequenos, apenas com a diferença de que dantes os golfinhos acompanhavam a nossa travessia quase colados ao casco e agora só há detergentes, petroleiros, manchas de óleo, enorme depósitos de petróleo das multinacionais deformando a outra margem (Lus, 29-30) 
Note-se que a travessia do rio permite introduzir, logo no primeiro capítulo, a metáfora marítima que percorre o romance indiciando de maneira subjacente o fracasso da nova gesta portuguesa: esta metáfora sublinha a oposição entre o período de apogeu da nação portuguesa, cantado por Camões em Os Lusíadas, e o presente vivido pelas personagens como decadente. Tudo anuncia a desgraça, a começar pela visão que tem J. C. de um homem que, ao afastar-se do cais lisboeta, lhe aparece como autêntica réplica do velho do Restelo:

[...] dos desastres em má hora anunciados por um velho de venerando aspecto, que ficara entre as gentes do cais, postos em nós os olhos, maneando três vezes a cabeça, descontente, a voz pesada um pouco alevantada, que nós no rio ouvimos claramente (Lus, 30).

O discurso do velho homem cruza-se no mesmo romance com as falas cheias de sabedoria de Moisés, o velho que tem a idade da personagem de Camões: ele tem "um saber só de experiência feito" (Lus, 157) que, conforme a figura bíblica evocada pelo seu nome, poderia salvar os povos em vias de perdição. Mas o desastre anunciado parece cumprir-se, e o texto de Camões, sendo demasiado jubilatório para o contexto descrito, é negativa e ironicamente matizado pela rápida evocação da História Trágico-Marítima: "mas isto é outra estória, cómico-marítima” (Lus, 30). O país parece estar a naufragar, pronto para se afundar nos meandros e sobressaltos da revolução: apresenta-se "sem leme, sem remos, sobrevivente na barca esburacada, metendo água por todos os lados, afundando-se" (Lus, 91). Pelo uso destas referências históricas e da intertextualidade de textos fundadores da literatura portuguesa, o autor denuncia a propensão dos Portugueses em sustentarem-se num passado dito glorioso, continuando a alimentar os seus mitos messiânicos, tendência analisada e largamente comentada por E. Lourenço:

Portugal, nascido e imposto por obra de uma Vontade ${ }^{7}$, de essência épica, um pouco alucinada, ora é encarnado e assumido positivamente pelo Herói que reactualiza com felicidade esse primeiro acto voluntário (Afonso Henriques, Nuno Álvares, Dom João II, Marquês de Pombal, Mouzinho da Silveira); ora mergulha em delírios e sonhos compensatórios absurdos, transformando-se na pátria de eleição do Milagre, do Sebastianismo, sinais equívocos de loucura empírica, tanto como promessa de ressurreição. (Lourenço, 1992, p. 94-95)

Assim os Portugueses fariam, iterativa, obstinada e, muitas vezes, hiperbolicamente, reviver as imagens do passado para encher um presente deficiente:

Portugal não espera o Messias, o Messias é o seu próprio passado, convertido na mais consistente e obsessiva referência do seu presente, podendo substituir-se-lhe nos momentos de maior dúvida sobre si ou constituindo até o horizonte mítico do seu futuro. (Lourenço, 1988, p. 10) 
Neste sentido, explorando ironicamente a intertextualidade com Os Lusíadas e a História Trágico-Marítima, obras que testemunham da epopeia das grandes descobertas dos séculos quinze e dezasseis, Almeida Faria leva o leitor a ler Lusitânia como uma antiepopeia: o texto, confirma L. S. Rebelo, tem "o ímpeto antiépico que intenta destruir a sedimentação provocada por sucessivas leituras de Os Lusíadas, instauradoras de um messianismo nacional, que toma a epopeia como a bíblia do destino português" (Rebelo, 1992, p. 17). Por outro lado, a paródia do discurso épico implica a contrastação com o quotidiano banal e sofrido das personagens que passam a ser anti-heróis: o percurso de todas elas reverte numa perda de esperança no futuro e num fracasso mais ou menos dramático, do exílio da personagem principal ao suicídio de Moisés. Por isso, Portugal é visto por João Carlos como um país que "chega de novo ao inultrapassável Cabo Não" (Lus, 229).

A paródia épica começa logo nas primeiras páginas pela desconstrução da imagem mítica das navegações lusíadas:

[...] um dia acabarão por pôr de parte essas arcaicas barcaças [os cacilheiros] que, numa regata de vapores, decerto não ganharão o primeiro prémio, contudo conquistaram um lugar na mitologia da cidade. São o que nos resta das descobertas e viagens, do apregoado império e seus naufrágios (Lus, 30).

O procedimento de demitificação passa também pela subversão de grandes feitos históricos como, por exemplo, a questão da escravatura ilustrada onírica e ironicamente pela venda de Marta como escrava (Lus, 38). A subversão da mitologia histórica portuguesa é aqui possibilitada pelo caráter oximórico do mito que Pierre Brunel evidenciou e definiu como "sistema de forças antagónicas, aliança de contrários” (Brunel, 1994, p. 37). Esta aliança é denunciada pelo próprio João Carlos: "Dir-se-ia lusitano destino navegar mesmo contra a maré" (Lus, 32). Nesta narrativa, a subversão do mito tem quase sempre a ver com uma noção de viagem. Assim acontece com a viagem utópica de Sónia a Angola onde ela pretende empenhar-se na revolução pós-independência: "O meu lugar agora é onde os frutos estão maduros para outros foguetes, onde ainda vai correr muito sangue antes que mudem as rédeas do poder" (Lus, 83). A viagem não menos utópica de João Carlos e de Marta a Veneza assevera a dimensão simbólica da relação conflituosa dos homens com a morte já que, como lembra Jean-Yves Tadié, "Veneza é o símbolo da morte, da arte, da degradação" (Tadié, 1994, p. 16-17). Também André, no fim do romance, parte para o Brasil no intuito de começar uma nova vida (Lus, 154). A escolha destes três destinos, três continentes intimamente ligados à hegemonia histórica de Portugal não é, como óbvio, mero acaso, reconstituindo-se assim o traçado do comércio triangular entre Portugal, África e Brasil, e abrindo a "uma revisitação do [nosso] imaginário imperial na hora exacta do seu definitivo crepúsculo" (Lourenço, 1987, p. 11-12). Entretanto, E. Lourenço propõe-nos uma interpretação complementar que tem a ver com uma tentativa de definição da 
alma portuguesa: "A fuga para céus mais clementes sempre se apresentou ao nosso horizonte português como último recurso perante obstáculos intransponíveis" (Lourenço, 1997, p. 112). Estes obstáculos insuperáveis estão, com certeza, na base dos pesadelos e visões aterrorizadoras que assombram dias e noites dos mais jovens, Tiago e Jó: o terror inspirado por animais fantásticos e ameaçadores traduzem, pois, a sua angústia perante a complexidade do presente e o seu medo do futuro (cap. 34):

O monstro não me larga, dormindo ou acordado encontro-o nesses corredores que não acabam, caminha com seus nojentos pés de porco, cada pata com dois cascados dedos adiante e dois atrás semelhando barbatanas, tromba capaz de foçar por tudo quanto é canto, ventas de olfacto fácil, ouvido fino, olho rápido, melena de cabelo negro hitlermente caindo com brilhantina no focinho, grossos presuntos desequilibrados em relação às canelas magras, cerdas aceradas saindo da barriga de toucinho, rabos enrolados iguais aos que a gente durante o carnaval pendura das costas e calças dos outros na escola sem eles darem por isso, inferno vivo este em que a gente vive. (Lus, 158-159)

No romance seguinte, Cavaleiro Andante, Jó imagina-se fugindo de casa à procura de liberdade, como fez o irmão João Carlos, e projeta-se na figura de um cavaleiro da Távola Redonda $\left(C A^{8}\right.$, cap.7), na demanda do Graal de que se aproximaram os Capitães de Abril, cavaleiros do século $\mathrm{XX}$, mas que apenas temporariamente o conseguiram alcançar.

Por entre as dificuldades sofridas pelas personagens, encontra-se também a impossibilidade de comunicarem, problemática paradoxal e simbolicamente enfatizada neste relato pela escolha do género epistolar. Pois, contrariamente à finalidade declarada da correspondência escrita, que é produzir um efeito de presença sublinhando a ausência do interlocutor ao estabelecer um diálogo à distância, os nossos epistolários não dialogam entre si: apenas constroem um simulacro de comunicação em que "cada personagem está encerrada em si, inscrito nas cartas que cada um é, mais do que envia, inventando-se, assim, nesta comunicação incomunicante, uma 'vida' [...]" (Lourenço, 1995, p. 3). Na realidade, esclarece o mesmo pensador noutro ensaio, "A estratégia epistolar mascara apenas essa incomunicabilidade radical de cada personagem e do singular universo silencioso que todos em conjunto constituem" (Lourenço, 1993, p. 238). Os correios cruzam-se sem haver verdadeiro intercâmbio de ideias e sentimentos, e estas incoincidências remetem para uma época anterior de imposição do silêncio e de negação do direito de expressão. Os filhos sentem esse peso herdado do poder patriarcal contra o qual não conseguiram lutar. Só em sonho conseguem fazê-lo como acontece com o menino Jó, evocando a figura severa e dominadora do pai: "Insurgi-me contra ele, contra o seu silêncio" (Lus, 61). Quanto à filha Marta, ela decide nunca ter filhos "a fim de não prolongar a cadeia de montagem da convenção, servidão e apatia", concluindo que nada teria acontecido da mesma maneira "se tivés- 
ssemos conversado ao longo de tantos anos de enganos, de ensurdecedor mutismo" (Lus, 73). A correspondência instaurada pela fragmentação da célula familiar investe o espaço lusófono e atravessa os oceanos à maneira dos navegadores de antanho, os epistolários escrevendo a partir dos lugares já referidos, mas não parecendo esperar resposta: as missivas não têm outro destinatário senão o seu próprio autor que, através da escrita, procura resolver o seu próprio enigma. Estamos numa altura em que é devolvida aos Portugueses a liberdade de expressão após cinco décadas de censura: o discurso político de facto se liberta e explode. No entanto, no domínio privado, as palavras continuam a cruzar-se sem se encontrarem, sofrendo ainda do peso do passado: a poder da herança recalca a vontade de o anular ou apenas de o desprezar.

A intenção de demitificar a revolução, e de insinuar que não permitiu uma verdadeira mudança, está claramente expressa no título do capítulo treze: "A revolução não altera em nada a vida de Jó e Tiago, no dia 26 de Abril" (Lus, 79). Aliás, como na maior parte dos romances da produção romanesca do pós-25 de Abril' ${ }^{9}$ o acontecimento é apenas indiretamente evocado, como se nada de verdadeiramente importante tivesse ocorrido naquele dia. O movimento dos capitães representou a esperança do regresso do "Desejado", ou seja, a realização de um grande destino ainda por vir, mas o messianismo do mito não funcionou e a esperança perdeu-se rapidamente numa resolução política não cumprida ou pelo menos por demais insuficiente e frustrante: o povo oprimido foi libertado, mas não recuperou a sua glória passada e não conseguiu criar um futuro correspondendo às expetativas revolucionárias. Por isso, a euforia grande e real que marcou os dias 25 de Abril e $1^{\circ}$ de Maio parece não ter eco nos comentários dos epistolários e não é tema de grande desenvolvimento. Apenas o André, o mais entusiástico, faz a Sónia uma descrição das manifestações de rua a apoiar o Movimento das Forças Armadas (Lus, 98-99), não sem expressar um certo ceticismo que lhe permite antever o que aconteceria pouco tempo a seguir com os desentendimentos partidários: “[...] festa, pura ilusão, fictícia unidade terminada logo que os interesses de cada grupo começarem a minar o corpo social" (Lus, 99). Arminda também mostra ter uma visão bastante clara do que se está a passar: evocando laconicamente a manifestação gigante do $1^{\circ}$ de Maio numa carta em que incita o irmão João Carlos a regressar a Portugal, não para emprenhar-se politicamente mas simplesmente para apoiar a família, ela aponta para os oportunismos políticos que efetivamente se declarariam nas semanas a seguir: "Pelo menos vem até cá ver o que isto é, o barulho que há aqui, a euforia extensiva a ex-legionários e ex-pides, agora bons democratas" (Lus, 123). João Carlos desaprova igualmente as práticas políticas corrompidas e fraudulentas de novos dirigentes: "Governos ditos de salvação naciona ${ }^{10}$ instauraram o salve-se-quem-puder, não nos salvam nem nos valem, tratam deles e dos seus" (Lus, 197). O rumo que a sociedade portuguesa está a tomar é criticado também por André: 
O novo-riquismo está a dar os primeiros passos, aparecem por todo o lado moradias cobertas de azulejos de casa de banho, berrantes, repugnantes, verdes, amarelos, roxo-rei, violeta, achados de pato-bravo que acabarão por tomar conta da brancura impecável das vilas (Lus, 166)

Por seu lado, Marta observa a falta de vontade coletiva e analisa-a também como uma herança do passado: “A 'pesada herança' está nisso, na passividade acumulada, no parasitismo das classes dominantes e, por imitação, das dominadas" (Lus, 173). A tendência para imitar o estrangeiro, o complexo da perda do império após a independência das antigas colónias, "a autopiedade de um povo desempregado desde Vasco da Gama" (Lus, 229) parecem constituir grande parte das causas da situação do país denunciada por J. C.: "o nosso secular cepticismo, indiferença, fatalismo, transformando em gesto nacional o encolher de ombros de outrora conhecido" (Lus, 220-221).

Clarividentes, todos exprimem igualmente a sua desilusão, a tonalidade dos discursos sendo de total desencanto e denotando uma disforia generalizada: "A tua carta trouxe-me o tom que imagino irá dominar na nossa casa: desfalecimento pelo falecimento, misturado de insegurança da mãe, medo do que aí venha, sensação de desânimo, interregno" (Lus, 93). A avaliação negativa pesa tanto que arrasta a denegação global do que foi positivamente cumprido. Os personagens são disso as vítimas simbólicas, a começar pela figura de J. C., sacrificados sobre o altar da revolução mas também vítimas da sua própria incapacidade de reagir e atuar. Vivem um tempo de desilusão, um presente de rutura total para com a sociedade que os gerou mas também consigo próprios. J. C. continuará à procura de uma possível definição identitária, mas quando se olha ao espelho apenas antevê a sua própria morte: "Hoje, olhei-me ao espelho e a minha futura morte apareceu-me com tal evidência, que tive dificuldade em reconhecer o que me fixava frio, estrangeiro na superfície lisa do vidro" (Lus, 187).

A indagação identitária é sem dúvida a questão chave deste texto. Acabamos de ver que o presente das personagens descompõe os sonhos heróicos dum Portugal mítico, exaltados pela ideologia salazarista, o que as desestabiliza profundamente e provoca neles um questionamento existencial que metonimicamente remete para o questionamento duma identidade nacional, preocupação que parece ser a do autor e da maior parte dos escritores do último quarto do século XX. A voz do autor, que se ouve através dos discursos das suas personagens, pode ser entendida como testemunho autobiográfico já que evoca uma época e coordenadas sociais e geográficas que correspondem ao que ele próprio viveu: o EU é ao mesmo tempo outro e o mesmo, como explica Philippe Lejeune no seu ensaio JE est un autre (1980). Assim sendo, este texto pode ser lido como uma crónica, dum tempo particular que se tornou histórico, que ficcionaliza uma parte da vida recente de uma nação, Portugal. A expressão epistolar fictícia múltipla reverte para a capacidade de interpretação do leitor que deve 
reconstituir a trama do romance, construir-lhe os significados a partir de fragmentos por vezes contraditórios, interpretando os diferentes pontos de vista num apanhado geral que permite fazer o retrato de uma coletividade.

Sabendo que o autor empírico pertence em próprio a essa coletividade, que o autor implicado expressa vários pontos de vista que convergem no mesmo sentido e derivados da sua própria visão, fazendo com que cada personagem a si se refletindo reflita o mundo, considerando ainda o pensamento de G. Gusdorf para quem o universo histórico apenas nos é acessível através dos seus reflexos nas existências individuais (Gusdorf, 1991, p. 452), afirmamos que este texto pode ser lido ao mesmo tempo como ficção autobiográfica e ficção historiográfica segundo o conceito desenvolvido por Linda Hutcheon, portanto, como biografia nacional em que o autor, de maneira totalmente subjetiva, reduz a experiência lusitana à dimensão de um fracasso coletivo e historicamente generalizado.

\section{REFERÊNCIAS BIBLIOGRÁFICAS}

FARIA, Almeida. Paixão [1a edição: 1965]. Lisboa: Portugália, 1965. . Cortes [1a edição: 1978]. Lisboa: Caminho, 1986. .Lusitânia [1a edição: 1980]. Lisboa: Caminho,1987.

.Cavaleiro Andante [1ª edição: 1983]. Lisboa: Caminho,1986.

BLANCKEMAN, Bruno. Les fictions singulières: étude sur le roman français contemporain. Paris: Prétexte Editeur, Critique, 2002.

BRUNEL, Pierre. "Mythe et littérature". Mythe et littérature, Etudes réunies et présentées par Ernst Leonardy. Université de Louvain: Recueil de travaux d'Histoire et de Philologie, 6e série Fascicule 47, p. 29-40, 1994.

GUSDORF, Georges. Auto-bio-graphie, Lignes de vie 2. Paris: Odile Jacob, 1991.

HALBWACHS, Maurice. La mémoire collective. Paris: Albin Michel. 1997.

HUTCHEON, Linda. Poética do pós-modernismo. História, teoria, ficção. Rio de Janeiro: Imago, 1991.

LEJEUNE, Philippe. JE est un autre. Paris: Seuil, 1980.

LEVÉCOT, Agnès. Le roman portugais contemporain, Profondeur du temps. Paris: L'Harmattan, 2009.

LOURENÇO, Eduardo. "Travessia de textos e busca de sinais no labirinto da morte”. Prefácio. In: FARIA, Almeida. Cavaleiro Andante. Lisboa: Caminho, 1987.

Nós e a Europa ou as duas razões. Lisboa: INCM, Col. Temas portugueses, 1988. 
- O Labirinto da Saudade, psicanálise mítica do povo português. Lisboa: Dom Quixote, 1992.

. O Canto e o Signo. Lisboa: Ed. Presença, 1993.

. "Errância e Busca num Imaginário Lusófono". In: Gilda Santos, Jorge Fernandes da Silveira, Teresa Cristina Cerdeira da Silva], [Informar autor ou orgs.]Cleonice Clara em sua geração, Org, , Rio de Janeiro: Editora UFRJ, 1995.

MAY, Georges. L'autobiographie. Paris: Presses Universitaires de France, 1979.

REBELO, Luís de Sousa. "Lusitânia ou os males da Pátria”. In: FARIA, Almeida. Lusitânia. Lisboa: 1992, p. 7-22.

RICCEUR, Paul. Mémoire, histoire et oubli. Paris: Seuil, Col. Points Essais $n^{\circ} 494,2000$. teur, 1994.

STÉTIÉ, Salah. Réfraction du désert et du désir. Mazamet: Babel édi-

TADIÉ, Jean-Yves. Le récit poétique. Paris: Tel Gallimard n²40, 1994.

Recebido para publicação em 31/10/18

Aprovado em 10/01/19

\section{NOTAS}

1 CREPAL (Centre de recherche sur les pays de langue portugaise), Sorbonne Nouvelle, Paris 3.

2 Abreviação que será usada no texto para referênciar o romance Lusitânia, Lisboa, Ed. Caminho, O Campo da Palavra, 1987, (1ª ed. 1980)

3 As traduções de todas as citações são da nossa responsabilidade.

4 Almeida Faria, Cortes, Lisboa, Ed. Caminho, O Campo da Palavra, 1986,(1ª ed. 1978).

$5 \mathrm{O}$ pai foi assassinado pelos trabalhadores da propriedade pouco antes do dia 25 de Abril em circunstâncias relatadas no capítulo 5 de Lusitânia (p. 51-53) numa carta de André dirigida ao irmão João Carlos.

6 Verso do Canto III de Os Lusíadas, de estudo obrigatório antes do 25 de Abril ("Esta é a ditosa pátria minha amada/A qual se o Céu me dá que eu sem perigo/Torne, com esta empresa já acabada/ Acabe-se esta luz ali comigo/Esta foi Lusitânia, derivada/De Luso, ou Lisa, que de Baco antigo/Filhos foram, parece, ou companheiros/E nela então os Íncolas primeiros").

7 Os grifos são da responsabilidade do autor.

8 Almeida Faria, Lisboa, Cavaleiro Andante, Ed. Caminho, O Campo da Palavra, $1987,\left(1^{\text {a }}\right.$ ed. 1983).

9 Cf. Levécot, Agnès, Le roman portugais contemporain, Profondeur du temps. Paris: L'Harmattan, 2009, p. 179-192.

10 No dia 25 de Abril de 1974, constituíram os militares uma Junta de Salvação Nacional que passou a assumir o poder após a destituição do Presidente da República Américo Tomás e do Presidente do Conselho Marcelo Caetano. 